\title{
EDITORIAL 2020.2
}

O Curso de Mestrado em Direito da Universidade Metodista de Piracicaba apresenta mais uma edição de Cadernos de Direito tendo por tema "Os Direitos Fundamentais Coletivos e Difusos".

Em um esforço conjunto, entre autores e colaboradores da Revista Cadernos de Direito, foi possível atender a demanda das submissões do segundo semestre de 2019 e do corrente ano, motivo pelo qual esta edição é mais extensa que as anteriores, o que dá a este número uma qualidade especial adicional.

$\mathrm{O}$ aspecto marcante foi a possibilidade de reunir pesquisadores de variados Estados brasileiros, fato que traz uma diversidade cultural que espelha as múltiplas realidades do país e com isso alcança-se um verdadeiro estudo cooperativo, baseado na troca de experiências e soluções.

A produção de conhecimento no Programa de Mestrado em Direito da Universidade Metodista de Piracicaba (UNIMEP) tem sido guiada pela sua área de concentração de pesquisa, que é o estudo e a produção no campo dos Direitos Fundamentais Coletivos e Difusos.

Os textos aqui apresentados trazem essa linha de trabalhar com fatos e como o Direito é a eles aplicado, sempre com o pano de fundo da proteção dos direitos fundamentais coletivos e difusos.

Sob este viés, os artigos científicos publicados abarcam os temas:

CONTROLE DE CONVENCIONALIDADE DA NOVA LEI DE MIGRAÇÃO: UMA OBSERVAÇÃO ACERCA DA QUESTÃO DOS REFUGIADOS NO BRASIL. Os autores, analisaram a convencionalidade da Nova Lei de Migração - Lei n ${ }^{\circ}$. 13.445/2017, especialmente no que diz respeito à questão dos refugiados, com o objetivo de observar a congruência normativa hierárquica existente entre a referida lei e os tratados internacionais de Direitos Humanos já ratificados pelo Brasil.

A RELEVÂNCIA DOS TRIBUNAIS DE CONTAS NO AUXÍLIO DO CONTROLE EXTERNO FRENTE À INEFICIENCIA DA ADMINISTRAÇÃO PÚBLICA. Os autores, abordaram assuntos atuais e relevantes acerca dos Tribunais de Contas e de sua indispensável participação nas atividades de controle externo, dando ênfase às precariedades de toda a sistemática política e administrativa em que estão inseridas as Cortes de Contas, bem como, na importância da autonomia e independência desses Tribunais. 
ROUSSEAU, O PARTICIPACIONISMO E ALGUMAS CRÍTICAS. O autor, abordou a teoria democrática do Participacionismo, instigado pela crise de representatividade da atualidade, apresentando breves linhas históricas acerca da origem dessa corrente, cujo primeiro uso do termo data de 1960, a partir de um movimento dos estudantes na Universidade de Michigan.

ELEMENTOS FUNDAMENTAIS DO PRESIDENCIALISMO DE COALIZÃO. As autoras, a partir de uma revisão bibliográfica sobre os principais fundamentos do presidencialismo desenvolvido em solo brasileiro, cuja principal característica é a coalizão, ou seja, a realização de alianças, destinadas, em tese, à garantia da governabilidade, examinaram os elementos do federalismo, do sistema eleitoral proporcional e de lista aberta e o multipartidarismo, com o fim de compreender e avaliar as coalizões efetuadas pelo Poder Executivo.

OS ELEMENTOS PARA O DESENVOLVIMENTO DE UM REGIME TRANSNACIONAL SUSTENTÁVEL DE PROTEÇÃO JURÍDICA DOS CONHECIMENTOS TRADICIONAIS ASSOCIADOS À BIODIVERSIDADE AMAZÔNICA. A autora, pesquisou a possibilidade da criação de elementos para o desenvolvimento de um regime transnacional sustentável de proteção jurídica dos conhecimentos tradicionais associados à biodiversidade amazônica, considerando a imprescindível inter-relação dos conhecimentos tradicionais dos povos da Amazônia com a sustentabilidade.

SUGESTÕES PARA O ALCANCE DAS DIMENSÕES DA SUSTENTABILIDADE NO TRATAMENTO DOS CONHECIMENTOS TRADICIONAIS ASSOCIADOS À BIODIVERSIDADE AMAZÔNICA. A autora, estudou as dimensões da sustentabilidade associada aos respectivos problemas, com o intuito de sugerir o alcance da sustentabilidade dos conhecimentos tradicionais associados à biodiversidade amazônica, considerando a imprescindível inter-relação dos conhecimentos tradicionais dos povos da Amazônia com a sustentabilidade.

TRATAMENTO JURÍDICO DA OBSOLESCENNCIA PROGRAMADA: UMA COMPARAÇÃO DE AÇÕES ENTRE O BRASIL, EUA E EUROPA. Os autores, analisaram a obsolescência programada, tecnicamente compreendida como a decisão do produtor de diminuir o tempo de vida útil de bens de consumo com o fim de maximização dos lucros, fato que passou a ser significativamente discutida a partir da constatação do exaurimento progressivo de matérias-primas, bem como, diante do aumento substancial da produção de lixo, a partir do comparativo de experiências do cenário atual dos Estados Unidos e da Europa.

CAPITAL DESTRUTIVO E AS CHAMADAS "VIOLENCIAS INOCENTES": UMA ANÁLISE DA TRAGÉDIA DE BRUMADINHO SOB A ÓTICA DA RESPONSABILIZA$C \zeta \tilde{A} O$ CIVIL. As autoras, no estudo realizado, objetivaram trazer à tona o caráter ambicioso, destrutivo e selvagem ínsito à atividade econômica capitalista em sua ânsia pelo lucro, no caso da tragédia de Brumadinho, abordando a importância de uma responsabilização cível e trabalhista justa, fundada em verdadeiros princípios de equidade e de dignidade da pessoa humana. 
IMPLICAÇÕES PENAIS DO LINCHAMENTO VIRTUAL COM FOCO NO COMPORTAMENTO SEXUAL DA MULHER: DISSEMINAÇÃO DO DISCURSO DE ÓDIO NAS RELAÇÕES DE GÊNERO SOB UMA PERSPECTIVA CRIMINOLÓGICA FEMINIS$T A$. Os autores, investigaram criticamente as implicações penais do linchamento virtual diante do comportamento sexual das mulheres, ponderando se e por que as mulheres são as vítimas preferenciais desse tipo de crime virtual e como essa dinâmica nociva tem se desenvolvido na dinâmica social moderna.

O TELETRABALHO COMO POLÍTICA PÚBLICA DE INCLUSÃO SOCIAL DAS PESSOAS COM DEFICIENNCIA NO BRASIL. Os autores, avaliaram as possibilidades do teletrabalho, lançando foco sobre a regulamentação dessa modalidade de trabalho, em especial no que se refere à nova redação do Artigo $6^{\circ}$ da Consolidação das Leis do Trabalho (CLT) e às inovações trazidas pela reforma trabalhista aprovada em 2017. Também se propõe uma reflexão sobre políticas públicas de emprego no Brasil e de inclusão social, mais especialmente no que tange às possibilidades para pessoas com deficiência ou dificuldades de mobilidade, que poderiam ser beneficiadas com a promoção do teletrabalho.

O PODER DE UMA EDUCAÇÃO LIBERTÁRIA NA DERRIBADA DE PARADIGMAS REPRESSIVOS: CONTRIBUIÇÕES MARXISTAS PARA A EMANCIPAÇÃO DO TRABA$L H A D O R$. As autoras, analisaram de que forma a educação pode ser um antídoto contra o retrocesso do Direito do Trabalho, a partir de reflexões marxistas de cunho educacional que encontram na educação libertária uma maneira de emancipar o trabalhador e retirá-lo dos grilhões da alienação mediante métodos que propiciem a recuperação da até então perdida consciência de classe, bem como, refletem a respeito da formação de um olhar crítico sobre a atual organização societária e a reconscientização do poder de luta do explorado para garantir melhores condições de labor e de vida.

A PROTEÇÃO À SAÚDE E A SEGURANÇA DO TRABALHADOR NO ARE 664.335: UMA ANÁLISE SOB A ÓTICA DA DIGNIDADE DA PESSOA HUMANA. A autora, fez uma análise crítica da concepção adotada pelo Supremo Tribunal Federal, no julgamento do Agravo em Recurso Extraordinário $n^{\circ} 664.335$, no que tange ao retrocesso social oriundo de tal decisão que, em tese de repercussão geral, acabou por fixar interpretação restritiva ao alcance de um direito essencial, qual seja, a aposentadoria, partindo de fundamentos altamente questionáveis, que ao final foram reafirmados na Emenda Constitucional de $\mathrm{n}^{\mathrm{o}}$. 103 de 2019, por ocasião da Reforma da Previdência.

O DIREITO À SAÚDE NO BRASIL - UMA ANÁLISE SOBRE O EXERCÍCIO DESSE DIREITO NO CONTEXTO DE PANDEMIA DA COVID-19. A autora, analisou o exercício do direito à saúde garantido constitucionalmente a todos aqueles que se encontrarem, em caráter temporário ou definitivo, em território brasileiro sob a perspectiva da pandemia oriunda do contágio pelo coronavírus.

A ORIGEM DAS FUNDAÇÕES PÚBLICAS DE DIREITO PRIVADO NA SAÚDE $B R A S I L E I R A$. As autoras, realizaram uma revisão teórica e histórica acerca da nova forma 
de prestação de serviços públicos de saúde brasileira, promovida por Fundações Públicas de Direito Privado, a partir da reforma gerencial do Estado.

A presente edição de Cadernos de Direito acredita que cada artigo aqui publicado possa contribuir de forma singular e efetiva, para a construção de um debate acadêmico produtivo e crítico do Direito, bem como de um conhecer jurídico alicerçado e atual.

Profa. Dra. Vivian A. Gregori Torres 